\title{
Another smoking hazard: raised serum IgE concentration and increased risk of occupational allergy
}

\author{
O ZETTERSTRÖM， K OSTERMAN， L MACHADO， S G O JOHANSSON
}

\begin{abstract}
Individual smoking histories of a general population sample and of two groups of workers exposed to occupational allergens were related to serum IgE concentrations and results of radioallergosorbent and prick tests in the workers.

The geometric mean IgE concentration was higher in smokers than in non-smokers. The distribution of serum IgE values in the two groups showed an apparent difference, with a bimodal appearance in the smokers. Evidence of sensitisation against occupational allergens was more common in workers who smoked.

The adjuvant effect of smoking on IgE antibody production might be due to damage to airways mucosa and supports the mucosal theory of atopy.
\end{abstract}

\section{Introduction}

In populations only rarely troubled with helminthic infections a high serum IgE concentration is mainly found in atopic subjects, who have an inherited predisposition to sensitisation and to develop specific IgE antibodies. ${ }^{12}$ The precise mechanism for the atopy is not known, but properties of the mucosa are probably important. ${ }^{3}$ Increased allergic sensitisation may occur in cystic fibrosis, ${ }^{4}$ cystic fibrosis heterozygosity, ${ }^{5}$ and anhidrotic congenital dysplasia. ${ }^{6}$ The risk of sensitisation in an individual also depends on the degree of exposure to a potential allergen. Studies of occupational allergy show that the greater the exposure the higher is the prevalence of sensitisation. "When examining workers from coffee roasteries with allergy to green coffee bean dust ${ }^{8}$ we observed that most of the sensitised subjects

\footnotetext{
University of Uppsala Department of Lung Medicine, University Hospital, S-750 14 Uppsala, Sweden

O ZETTERSTRÖM, MD, assistant professor

K OSTERMAN, MD, consultant

L MACHADO, MD, physician
}

Department of Clinical Immunology, Karolinska Sjukhuset, S-104 01 Stockholm, Sweden

S G O JOHANSSON, MD, professor and head of department were smokers and that the workers who smoked had higher IgE concentrations. To study further the relation between smoking habits, allergic sensitisation, and IgE values we have now investigated a representative sample of the population and two groups of workers exposed to occupational allergens.

\section{Subjects and methods}

Population sample-Reference sera had been collected from 246 subjects attending a health check-up programme in Uppsala county. Total serum IgE values were measured in all subjects, and all answered a questionnaire about symptoms of a possible allergic nature. To ensure as far as possible that the sample was non-atopic we excluded 59 subjects reporting symptoms and 12 others with a positive radioallergosorbent test result or three or more positive skin test results. Hence 175 probably non-atopic subjects were available for study (for details, see Zetterström and Johansson²). The smoking habits of all 246 subjects were obtained by postal questionnaire. If there was no reply to the first questionnaire a second one was sent. If the subject still failed to reply he or she was interviewed by telephone. In this way data on smoking were obtained from 236 subjects. Of the remainder, two had left the country, three were dead, and five could not be traced.

Workers in pharmaceutical industry-All 60 workers in a pharmaceutical factory who were exposed to ispaghula powder were investigated. Ispaghula powder, which is the grained epidermal layer of the seeds of Plantago ispaghula, is used in bulk laxatives and is a potent allergen when airborne. ${ }^{9} \mathrm{~A}$ detailed case history, smoking history, and a serum sample were collected from all workers. Measurement of total serum IgE values and radioallergosorbent tests against ispaghula and common allergens (according to case history) were performed.

Workers in coffee roastery-All 139 workers at a large roastery who were present on one day were asked to undergo skin-prick tests with green coffee bean and castor bean extracts. A total of 129 agreed to the tests and were also interviewed about their smoking habits.

Allergy tests-IgE was determined by the paper radioimmunosorbent test (Phadebas IgE PRIST, Pharmacia Diagnostics AB, Uppsala), and IgE antibodies by the radioallergosorbent test with allergen-coated filter-paper discs. An immunosorbent purified anti-IgE with $D \varepsilon_{2}$ specificity was used in the tests. ${ }^{10}$ The allergen extract from green coffee bean dust was prepared by extraction in Coca's fluid $(1 / 10 \mathrm{w} / \mathrm{v})$ followed by chromatography on Sephadex G 50. The active fractions were identified by the radioallergosorbent tests, pooled, and used in the skin-prick test. A freeze-dried castor bean extract was used in a concentration of $1 \mu \mathrm{g} / \mathrm{ml}$ in the skin-prick test. Ispaghula powder was mixed with Coca's fluid in a concentration 
of $1 / 100 \mathrm{w} / \mathrm{v}$ to give the extract used in the radioallergosorbent test. The skin tests were made by gently pricking with a tuberculin needle through a drop of allergen extract placed on the volar aspect of the forearm. ${ }^{7}$

Statistical-Student's $t$ test was used to evaluate differences of means of logarithmically transformed IgE values. Comparisons of observed frequencies were made by Fisher's exact test.

\section{Results}

The geometric mean IgE concentration in the whole population sample was $16.5 \mathrm{kU} / 1$. The smoking group, which included those who had given up smoking within one year before sampling, comprised 107 subjects and the non-smoking group 129. The smokers were originally subdivided according to their smoking habits-for example, less than 10 cigarettes a day, more than 10 cigarettes a day, pipe smokers, exsmokers, etc. As some of the groups were small, however, and the

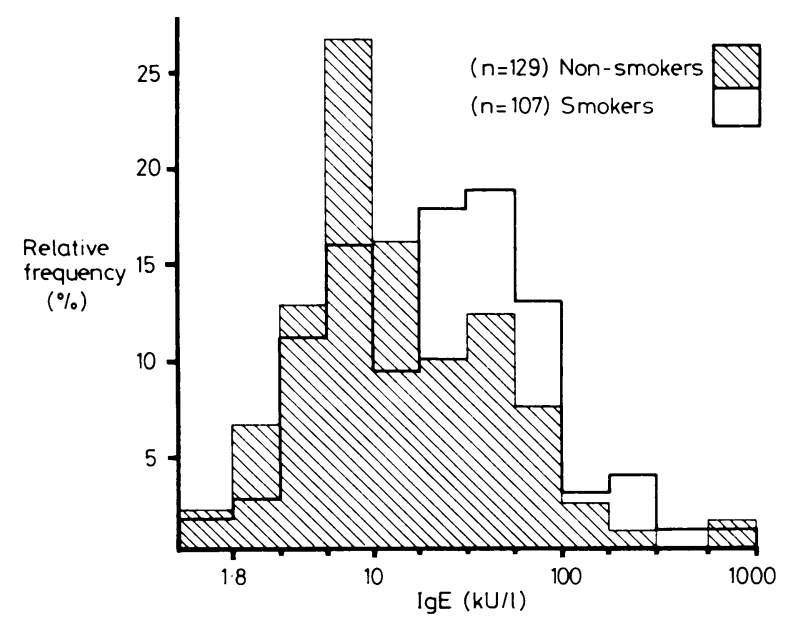

FIG 1-Distribution of serum IgE concentrations in non-smokers and smokers from general health survey.

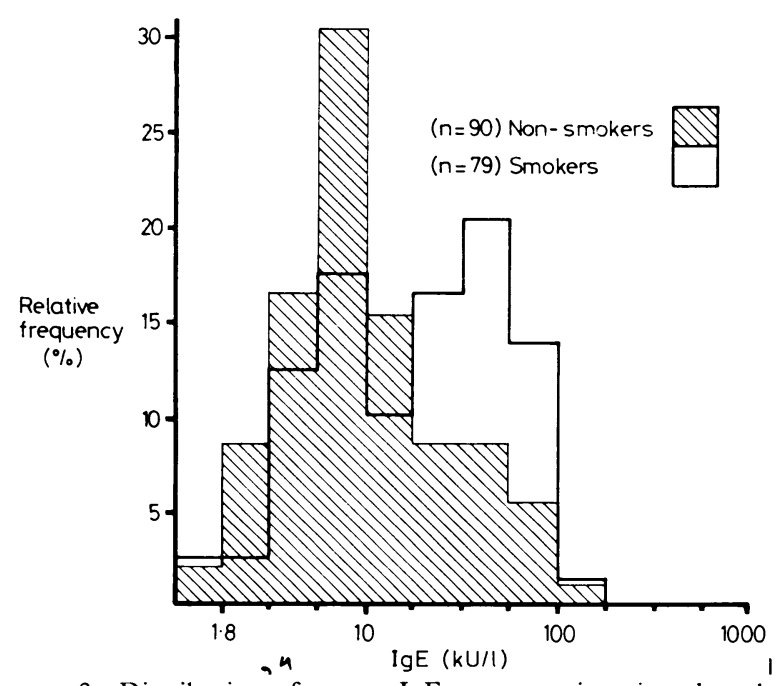

FIG 2-Distribution of serum IgE concentrations in selected, probably non-atopic subjects from health survey.

TABLE I-Results of radioallergosorbent tests to ispaghula allergen and six common allergens in 60 workers exposed to ispaghula dust

\begin{tabular}{lcccccc}
\hline & \multicolumn{2}{c}{ Ispaghula allergen } & & \multicolumn{2}{c}{ Common allergens } \\
\cline { 2 - 3 } \cline { 5 - 6 } & Negative & Positive & & Negative & Positive \\
\hline Non-smokers $(\mathrm{n}=23)$ & 22 & $1^{*}$ & & 21 & 2 \\
Smokers $(\mathrm{n}=37)$ & 29 & $8^{*}$ & & 34 & 3
\end{tabular}

$* \mathrm{p}<0.04$ distributions and geometric mean values of $\mathrm{IgE}$ did not differ significantly, they were taken together as one single group for comparison with non-smokers. The geometric mean IgE concentration in the smokers was $20.8 \mathrm{kU} / 1$ and in the non-smokers $13.2 \mathrm{kU} / \mathrm{l}$. This difference was significant $(\mathrm{p}<0.01)$.

In the 175 non-atopic subjects drawn from the population sample the IgE concentrations were lower and the geometric mean value 13.4 $\mathrm{kU} / \mathrm{l}$. Smoking data were obtained in 169 of them; 90 were nonsmokers and 79 smokers, and the mean IgE concentrations were $9 \cdot 7$ and $17.6 \mathrm{kU} / 1$ respectively. This difference between non-smokers and smokers was highly significant $(\mathrm{p}<0.001)$.

To study the distribution of IgE values in smokers and non-smokers we constructed a histogram with logarithm class intervals. This showed an apparent difference between the two groups (fig 1), which was more evident in the selected group of non-atopic subjects. In the smokers the values showed a bimodal distribution, with one peak in the range $5 \cdot 6-10 \cdot 0 \mathrm{kU} / 1$ and the other in the range $32-56 \mathrm{kU} / 1$ (fig 2).

Workers in pharmaceutical industry-In this group higher serum IgE concentrations were also found in smokers than in non-smokers. The geometric mean values were 41.5 and $22.8 \mathrm{kU} / \mathrm{l}$, respectively. This difference, however, was not significant. Nine of the 60 workers had atopic symptoms and specific IgE antibodies to ispaghula allergen as detected by the radioallergosorbent test. Eight of them were smokers. This increased prevalence in smokers was significant $(p<0.04)$. Table I gives the results of the radio allergosorbent tests in the smokers and non-smokers.

Coffee workers-Table II gives the results of skin tests with green coffee bean and castor bean extracts in the non-smoking and smoking coffee workers. With both allergens a significantly increased prevalence of positive skin-prick tests was found in the smokers $(p<0.01)$. The positive prick tests most probably represented IgE-mediated reactions. A good correlation between prick tests, occurrence of specific $\operatorname{IgE}$ antibodies, and atopic symptoms was found in our first investigation. ${ }^{8}$ In this study 22 out of 28 workers with positive skin test results had atopic symptoms, mostly rhinoconjunctivitis, but six had asthma and three had skin lesions.

TABLE II-Prick-test results with extracts of raw coffee dust and castor bean

\begin{tabular}{|c|c|c|c|c|}
\hline & \multicolumn{2}{|c|}{ Raw coffee dust } & \multicolumn{2}{|c|}{ Castor bean } \\
\hline & Negative & Positive & Negative & Positive \\
\hline $\begin{array}{l}\text { Non-smokers }(n=59) \\
\text { Smokers }(n=70)\end{array}$ & $\begin{array}{l}55 \\
50\end{array}$ & $\begin{array}{r}4^{*} \\
20^{*}\end{array}$ & $\begin{array}{l}54 \\
53\end{array}$ & $\begin{array}{r}5+ \\
17^{+}\end{array}$ \\
\hline
\end{tabular}

\section{Discussion}

Of the several investigations of serum IgE concentrations in various populations, apparently only one has detected different values between smokers and non-smokers. ${ }^{11}$ This may be because the difference is relatively small-much smaller than between atopic and non-atopic subjects-and the fact that most IgE values are low. A sensitive method like the Phadebas IgE PRIST or a double-antibody radioimmunoassay must be used for accurate measurement of low IgE concentrations. ${ }^{12}$ According to Marsh et al, ${ }^{1}$ the occurrence of significant amounts of specific IgE antibodies is linked to the total $\operatorname{IgE}$ value. This agrees with our findings of both higher IgE concentrations and an increased risk of sensitisation in smokers.

Increased atopic sensitisation in smokers might lead to an overrepresentation of allergic diseases among them. Asthma was also more common in smokers in a population study which, like ours, was made with the help of the continuously run health survey in Uppsala county. ${ }^{13}$ The correlation was statistically significant only for women and was less evident with age. The relatively weak association between smoking and asthma might be explained by a tendency for asthmatics to give up smoking. ${ }^{13}$

A high prevalence of asthma with positive skin tests associated with smoking and air pollution was reported in studies of the so-called Tokyo-Yokohama asthma. ${ }^{14}$ An explanation for the effect of smoking on IgE antibody production would be that smoking damages the airway mucosa and affects the handling of inhaled antigens, so promoting a shift in antibody production 
from IgG to IgE. Low serum IgG and high IgE concentrations in smokers were found by Gerrard et al. ${ }^{11}$ That smoking may influence the immunological response is also indicated by the fact that it is mostly non-smokers who develop IgG antibodies and extrinsic allergic alveolitis on exposure to airborne antigens. ${ }^{1516}$ The increased atopic sensitisation in persons with inherited mucosal defects ${ }^{4-6}$ supports this theory, which fits the concept of a mucosal factor in the pathogenesis of atopy. ${ }^{3}$ The report of an association between viral infections, increase in serum IgE concentration, and sensitisation in children may also be explained by a transient mucosal defect. ${ }^{17}$

The prevalence of atopic diseases seems to have increased, especially in industrialised countries. Allergic rhinitis, for instance, was apparently rare at the beginning of the nineteenth century, while it is now common. Such a rapid increase cannot be explained by a change in man's genetic constitution; it is also unlikely that an augmentation in exposure to allergens, such as pollens and animal dander, has occurred. Exposure to substances that irritate the bronchi, however, has probably increased, and if IgE antibody production is enhanced by mucosal damage this offers an explanation for the increase of atopic airway disease. Blackley's comment in 1873 seems remarkably foresighted: "Perhaps this [increase] may in part be due to increased attention ... but it may also be accounted for by the greater prevalence of those conditions which act as predisposing and exciting causes." ${ }^{*}$ Air pollution and tobacco smoking may be such predisposing causes.

We are grateful for the secretarial help of Mrs Christina Gozzi, of the Uppsala county health authorities, and for the statistical advice from Mr Göran Nilsson, department of applied mathematics, Pharmacia AB, Uppsala. Allergen-coated filter-paper discs used in the radioallergosorbent test for IgE antibodies were kindly supplied by the research department of Pharmacia Diagnostics AB. We also thank Dr R Panzani (Marseilles) for the freeze-dried castor bean extract, and Draco AB, Lund, for the ispaghula powder. This work was supported in part by grants from the Swedish National Association against Heart and Chest Diseases, the Swedish Medical Research Council (Grant No 16 X -105), and Astma/allergiföreningen.

\section{References}

${ }^{1}$ Marsh DG, Bias WB, Ishizaka K. Genetic control of basal serum immunoglobulin $\mathrm{E}$ level and its effect on specific reaginic sensitivity. Proc Natl Acad Sci USA $1974 ; 71: 3588-92$.

${ }^{2}$ Zetterström O, Johansson SGO. IgE concentrations measured by PRIST in serum of healthy adults and in patients with respiratory allergy: a diagnostic approach. Allergy (in press).

${ }^{3}$ Leskowitz S, Salvaggio JE, Schwartz HJ. An hypothesis for the development of atopic allergy in man. Clin Allergy 1972;2:237-46.

4 Warren CPW, Tai E, Batten JC, Hutchcroft BJ, Pepys J. Cystic fibrosis -immunological reactions to a fumigatus and common allergens. Clin Allergy 1975;5:1-12.

${ }^{5}$ Warner JO, Norman AP, Soothill JF. Cystic fibrosis heterozygosity in the pathogenesis of allergy. Lancet 1976;i:990-1.

${ }^{6}$ Vanselow NA, Yamate M, Adams MS, Callies Q. The increased prevalence of allergic disease in anhidrotic congenital ectodermal dysplasia. fournal of Allergy 1970;45:302-9.

${ }^{7}$ Pepys J, Davies RJ. Occupational asthma. In: Middleton E, Reed CE, Ellis E, eds. Allergy principles and practice. Saint Louis: C V Mosby, 1978:812-42.

${ }^{8}$ Osterman K, Johansson SGO, Zetterström O. Allergy to coffee bean dust. Allergy 1978; 33:350.

${ }^{9}$ Machado L, Fagerberg E, Zetterström O. Occupational allergy in nurses to a bulk laxative. Allergy $1979 ; 34: 51-5$

10 Bennich H, Johansson SGO. Immunoglobulin $\mathrm{E}$ and immediate hypersensitivity. Vox Sang 1970;19:1-3.

11 Gerrard JW, Heiner DC, Ko CG, Mink J, Meyers A, Dosman JA. Immunoglobulin levels in smokers and non-smokers. Ann Allergy $1980 ; 44: 261-2$

12 Nye L, Merret TG, Landin J, White RJ. A detailed investigation of circulating IgE levels in a normal population. Clin Allergy $1975 ; 5: 13-24$

${ }^{13}$ Kiviloog J, Irnell L, Eklund G. The prevalence of bronchial asthma and chronic bronchitis in smokers and non-smokers in a representative local Swedish population. Scand $\mathcal{F}$ Respir Dis 1974;55:262-76.

14 Tremonti LP. Tokyo-Yokohama asthma. Ann Allergy 1970;28:590-5.

${ }^{15}$ Morgan DC, Smyth JT, Lister RW, Pethybridge RJ. Chest symptoms and farmers' lung: a community survey. Br f Ind Med 1973;30:259-65.

16 Warren CPW. Extrinsic allergic alveolitis: a disease commoner in nonsmokers. Thorax 1977;32:567-9.

17 Frick OL, German DF, Mills J. Development of allergy in children. I. Association with virus infections. $\mathcal{F}$ Allergy Clin Immunol 1979;63: 228-41.

${ }^{18}$ Blackley CH. Experimental research on hay fever. (1873.) New ed. Pall Mall, London: Dawson, 1959:5.

(Accepted 27 fuly 1981)

\title{
Fracture of neck of the femur: changing incidence
}

\author{
A FENTON LEWIS
}

\begin{abstract}
From 1959 to 1977 the numbers of hospital admissions for fracture of the neck of the femur increased by a factor of 2.7. Detailed analysis of data from the Hospital In-Patient Enquiry for 1968-77 showed that the increase applied to both sexes and at all ages over 45 . The true incidence rate increased in parallel with the admission rate, and only a small part of the increased number of admissions was explained by the increasing numbers of the elderly.

The increasing incidence of fracture of the neck of the femur imposes great strain on hospital resources, particularly trauma and orthopaedic departments, and merits urgent investigation. An explanation for the increase might be that the experience of one demand-led condition characterises a greater need for health care among the elderly for other conditions.
\end{abstract}

Department of Health and Social Security, London SE1 6TE A FENTON LEWIS, MB, PHD, senior medical officer

\section{Introduction}

Our ability to estimate the incidence of fracture of the neck of the femur in the national population depends on careful interpretation of hospital activity data. The Hospital In-Patient Enquiry consists of a 10\% subset of hospital activity data and counts patients at the time of discharge or death, but the diagnosis is that pertaining at the time of admission. For simplicity these figures are described here as admissions.

\section{Hospital admissions}

Figure 1 shows the trend from 1959 to 1977 for England and Wales. Over the 18 years admissions for fracture of the neck of the femur increased nearly threefold, and except for a peak during the adverse winter of 1963 the trend was stable from year to year. Two other conditions are shown for comparison-namely, fracture of the skull and face and fracture of some other part of the femur. These showed a paitern over time closely similar to admissions for all conditions.

The 10-year period 1968-77 was examined in more detail. This avoided the early phase of development of the Hospital In-Patient Enquiry and gave a period where constant quality of data and reasonable consistency of clinical practice in treating the condition might be 